\title{
Influência da folga financeira na estrutura de capital em empresas de alimentos brasileiras, chilenas e mexicanas
}

\author{
Influence of financial slack on the capital structure in brazilian, chilean and mexican food \\ companies
}

Influencia de la holgura financiera en la estructura de capital de las empresas de alimentos brasileña, chileña y mexicaña

\section{Edgar Pamplona}

Doutorando em Ciências Contábeis e Administração pelo Programa de Pós-Graduação em Ciências Contábeis (PPGCC) da Universidade Regional de Blumenau (FURB)

Endereço: Rua Antônio da Veiga, 140, Sala D202 - Victor Konder

CEP: 89.031-900 - Blumenau/SC - Brasil

E-mail: edgarpamplona@hotmail.com

Telefone: (47) 3321-0565

\section{Daniel Fernando Padilha}

Mestre em Ciências Contábeis pelo Programa de Pós-Graduação em Ciências Contábeis (PPGCC) da Universidade Regional de Blumenau (FURB)

Endereço: Rua Antônio da Veiga, 140, Sala D202 - Victor Konder

CEP: 89.031-900 - Blumenau/SC - Brasil

E-mail: danielpadilha06@hotmail.com

Telefone: (47) 3321-0565

\section{Tarcísio Pedro da Silva}

Doutor em Ciências Contábeis e Administração pelo Programa de Pós-Graduação em Ciências Contábeis (PPGCC) da Universidade Regional de Blumenau (FURB)

Professor do Programa de Pós-Graduação em Ciências Contábeis (PPGCC) da Universidade Regional de Blumenau (FURB)

Endereço: Rua Antônio da Veiga, 140, Sala D202 - Victor Konder

CEP: 89.031-900 - Blumenau/SC - Brasil

E-mail: tarcisio@furb.br

Telefone: (47) 3321-0565

Artigo recebido em 12/04/2016. Revisado por pares em 16/11/2017. Reformulado em 13/034/2018. Recomendado para publicação em 15/06/2018 por Carlos Eduardo Facin Lavarda Editor-Chefe). Publicado em 30/06/2018. 


\title{
Resumo
}

Este estudo teve como objetivo examinar a influência da folga financeira na estrutura de capital das empresas de alimentos brasileiras, chilenas e mexicanas. Trata-se de uma pesquisa descritiva, documental e quantitativa. O período de estudo compreende os anos de 2009 a 2013, tendo como amostra 29 organizações. Os resultados mostram a folga financeira como fator determinante da estrutura de capital das empresas de alimentos nos três países, apresentando influência negativa sobre o endividamento de curto prazo (no Brasil, Chile e México) e total (no Brasil), bem como positiva sobre o endividamento de longo prazo (no Chile e México). Desta forma, pode-se identificar que as empresas tendem a constituir folga financeira com recursos próprios inicialmente, aderente à teoria pecking-order, mas quando não possível por este meio, utilizam recursos de terceiros de longo prazo para usufruir dos benefícios vinculados a folga financeira. Além disso, as relações encontradas são mais próximas entre empresas chilenas e mexicanas comparativamente as organizações brasileiras.

Palavras-chave: Estrutura de capital; Folga Financeira; Empresas de alimentos; Brasil, Chile e México

\begin{abstract}
The purpose of this study was to examine the influence of financial slack on the capital structure of brazilian, chilean and mexican food companies. This is a descriptive, documentary and quantitative research. The study period covers the years 2009 to 2013, with a sample of 29 organizations. The results show the financial slack as a determinant factor of the capital structure of food companies in the three countries, with a negative influence on short-term debt (in Brazil, Chile, and Mexico) and total indebtedness (in Brazil), as well as positive on its longterm indebtedness (in Chile and Mexico). In this way, it can be identified that the companies tend to constitute financial slack with their own resources initially, adhering to the peckingorder theory, but when not possible by this means, use long-term third-party resources to enjoy the benefits linked to financial slack. In addition, the relations found closer between chilean and mexican companies compared to brazilian companies.
\end{abstract}

Keywords: Capital structure; Financial slack; Food companies; Brazil, Chile and Mexico

\section{Resumen}

Este estudio tuvo como objetivo examinar la influencia de la holgura financiera en la estructura de capital de las empresas de alimentos brasileñas, chilenas y mexicanas. Se trata de una investigación descriptiva, documental y cuantitativa. El periodo de estudio comprende los años 2009 a 2013, teniendo como muestra 29 organizaciones. Los resultados muestran la holgura financiera como factor determinante de la estructura de capital de las empresas de alimentos en los tres países, presentando una influencia negativa sobre el endeudamiento a corto plazo (en Brasil, Chile y México) y total (en Brasil), así como positiva sobre endeudamiento a largo plazo (en Chile y México). De esta forma, se puede identificar que las empresas tienden a constituir holgura financiera con recursos propios inicialmente, adherido a la teoría peckingorder, pero cuando no es posible por este medio, utilizan recursos de terceros a largo plazo para usufructuar de los beneficios vinculados a la holgura financiera. Además, las relaciones encontradas más cercanas entre empresas chilenas y mexicanas en comparación con las empresas brasileñas.

Palabras clave: Estructura de capital; Holgura Financiera; Empresas de alimentos; Brasil, Chile y México 


\section{Introdução}

Algumas décadas se passaram desde os primeiros estudos sobre estrutura de capital. O trabalho de Myers (1984) afirmava que não se conhecia a política de dividendos de uma empresa, mas que mudanças significativas na estrutura de capital forneciam informações aos investidores. Todavia, Campos e Nakamura (2013) mencionam que mesmo com o desenvolvimento de estudos empíricos ao longo das décadas, ainda não se tem um conhecimento profundo dos fatores que determinam o endividamento de uma empresa.

Alguns trabalhos dessa linha de pesquisa costumam testar duas importantes teorias que é a trade-off advinda inicialmente de Modigliani e Miller $(1958 ; 1963)$ e a pecking order defendida por Myers (1984) e Myers e Majluf (1984), na qual a primeira teoria, trade-off, assevera que o valor da empresa é maximizado quando a organização atinge seu endividamento ótimo, que deve ser dimensionado pelos custos e benefícios da dívida, sendo os benefícios vinculados principalmente ao benefício fiscal e os custos pelo aumento da probabilidade de falência e/ou embaraço financeiro da organização. Já a segunda teoria, pecking order, defende que a empresa busca financiamento por intermédio de uma hierarquia, priorizando inicialmente as fontes de recursos internas em detrimento as de terceiros (sejam elas dívidas ou emissão de novas ações, respectivamente), visto que a menor assimetria informacional faz com que fontes internas, que conhecem o negócio, concedam capital a organização por custo inferior, maximizando, por consequência, o valor corporativo.

Diante desse contexto, as referidas teorias são aplicadas a ambientes diversificados, como apresentado no estudo de Hoffmann (2009) que analisa a estrutura de capital das empresas pertencentes ao Índice de Preços Seletivo (IPSA) no Chile. Em suma, observou-se que as organizações pertencentes ao referido índice têm maior visibilidade no mercado, reduzindo a assimetria e fornecendo, por consequência, maior acesso a fontes de financiamento externo. $\mathrm{O}$ trabalho de Bastos e Nakamura (2009), por sua vez, verificou a estrutura de capital das empresas da América Latina, fazendo comparação entre os países Brasil, Chile e México no período de 2001 a 2006 e, conforme achados encontrados, se verificou que no Brasil e no México a teoria pecking order melhor explica a forma como as empresas estruturam seu capital, enquanto no Chile os preceitos da teoria de trade-off são mais aderentes as observações.

Salienta-se ainda que a observância da estrutura de capital pode ser encontrada na literatura em setores específicos, o que contempla melhor comparabilidade. Neste sentido, Anggono e Pertiwi (2013) examinaram a estrutura de capital em empresas de alimentos e bebidas da Indonésia, partindo do entendimento de que a forma como as organizações buscam recursos influencia no valor das empresas. Mais especificamente entre os períodos, foi observado que o WACC - Custo Médio Ponderado de Capital - em 2008 apontou que a relação dívida efetiva e capital próprio não estavam em condições ideais, enquanto de 2009 a 2011 inúmeras empresas da amostra apresentaram ótima relação dívida e capital próprio, reduzindo assim o WACC e maximizando o valor da empresa.

Ademais, destaca-se que um dos principais fatores que pode impactar na escolha de estrutura de capital por parte das organizações é a folga financeira. Denis (2011), partindo do entendimento de que as finanças externas são dispendiosas, defende que as empresas possuem incentivos claros de acumular dinheiro a fim de constituir folga financeira, visando evitar consequências adversas associadas a choques nos lucros ou oportunidades de investimento (Denis, 2011) pratica que seria consistente com a teoria de pecking-order. Todavia, um questionamento que surge é porque nem todas as empresas recorrem a esta prática visando assegurar os investimentos no menor nível (DENIS, 2011). 
Diante desse contexto, é perceptível a necessidade de realização de novas pesquisas, visando compreender o complexo fenômeno em questão. Desta forma, com o intuito de contribuir para com a literatura acerca do tema, emerge-se a seguinte questão: qual a influência da folga financeira na estrutura de capital das empresas de alimentos brasileiras, chilenas e mexicanas? Visto a questão de pesquisa, o objetivo desse estudo, por consequência, é examinar a influência da folga financeira na estrutura de capital das empresas de alimentos brasileiras, chilenas e mexicanas.

O estudo justifica-se, inicialmente, pela importância das investigações na área, como garantem Correa, Basso e Nakamura (2013), visto que pesquisas sobre estrutura de capital são consideradas dentre as mais relevantes na área de finanças. Além disso, quanto à folga financeira, Zhong (2011) menciona que apesar de sua importância, a literatura existente ainda não fornece formulações consistentes a seu respeito (ZHONG, 2011), seja em influencia ao desempenho da empresa ou a suas escolhas de estrutura de capital, o que abre espaço para novas pesquisas. Para Denis (2011), empresas com recursos internos mais abundantes, sendo parte deles alocados como folga financeira, são mais propensas a investir melhor quando das oportunidades, visto que não precisam recorrer a financiamentos externos (DENIS, 2011), impactando nas decisões de estrutura de capital e, consequentemente, no valor da empresa.

De fato, Campos e Nakamura (2013) defendem que o objetivo primário de uma organização é maximizar o valor sob uma perspectiva de longo prazo a fim de satisfazer principalmente acionistas e credores e, como objetivo secundário, tem-se o de sobreviver a choques, sejam estes internos ou externos no curto prazo (CAMPOS \& NAKAMURA, 2013). Logo, compreender a folga financeira e sua relação com a estrutura de capital torna-se imprescindível, visto que tais decisões impactam em ambos os objetivos descritos, ou seja, no valor da empresa e na capacidade destas de se manterem competitivas no mercado.

Além disso, o estudo aborda um importe setor econômico mundial e que está em processo de crescimento. Fiorentino et al. (2012) destaca que o consumo de alimentos eleva-se em função do crescimento da população e vem sendo amplificado também pela industrialização das economias emergentes, como é o caso do Brasil, Chile e México. Benachenhou (2013), em um amplo estudo sobre os países emergentes, destacou algumas características das nações aqui objeto de estudo. Em referência específica ao Brasil, destaca que, durante os anos recentes, o país surgiu no mercado mundial como potência agrícola, porém não se limita a este setor, pois as exportações não agrícolas também se diversificaram e se desenvolverem, sendo que, o Brasil se tornou uma superpotência na produção de açúcar, café, carne bovina, aves, soja, entre outras.

Em referência ao Chile, este se destaca em nível mundial como o maior exportador de blueberries, uvas, ameixas, maçãs secas, truta e salmão do pacífico. Noventa por cento $(90 \%)$ das exportações chilenas são por mar, com uma eficiência 3,2 vezes maior do que o transporte terrestre utilizado na Europa e nos EUA. Além disso, o país é considerado líder em exportação de alimentos da América Latina (PROCHILE, 2014). Os grandes grupos agros alimentares mundiais estão presentes no Chile, e os grupos chilenos conseguiram internacionalizar-se em direção ao México e a Argentina, sendo que, a indústria agroalimentar chilena exporta 300 produtos diferentes para 40 países (BENHACHENHOU, 2013).

Por fim, em referência a economia mexicana, Casas (1993) observou que historicamente o país tem longa experiência no desenvolvimento de alimentos e de pesquisa agrícola, uma vez que recebeu grande impulso do estado a partir de 1930. Mediante esta abrangência no setor, Garcia (2013) relata que, o indicador de empregos no agroalimento entre 1980 e 2010 traz vários países representativos pelo mundo, e as maiores proporções são encontradas na América do Sul, essencialmente no Brasil e no México. Isso também é constatado por Benachenhou 
(2013), relatando que grandes grupos mexicanos cresceram em diversos setores industriais, entre eles o agroalimentar.

Cabe destacar ainda que a comparação entre países é importante, visto que conforme Bastos, Nakamura e Basso (2009), por conta da influência ambiental sobre o desempenho das empresas, tem-se observado um maior número de estudos teóricos e empíricos que consideram não apenas empresas de um único país. Assim, a tendência verificada é expandir as pesquisas sobre os determinantes de estrutura de capital para organizações situadas em contextos diversos, a fim de encontrar evidências mais robustas sobre a estrutura de capital das organizações.

\section{Revisão da Literatura}

\subsection{Estrutura de Capital}

Iniciando pela teoria clássica, Durand (1952) relatava que se tem ouvido sobre uma admitida escassez de capital, sendo observado que muitas empresas financiam expansão com dinheiro retido de operações ou por meio de empréstimos. Isso pode significar, como argumentado a época, que secaram-se as habituais fontes de capital social. Posteriormente, numa abordagem neoclássica acerca do uso de capital pelas entidades, Modigliani e Miller (1958) relataram que o custo de capital para os proprietários de uma empresa é simplesmente a taxa de juros de títulos e, derivou a proposição que a empresa, agindo racionalmente, utilizará um dos dois critérios de decisão consciente, que são equivalentes ao abrigo de segurança, correspondentes a maximização dos lucros e a maximização do valor de mercado da empresa.

Com relação à maximização dos lucros, Modigliani e Miller (1958) destacam que vale a pena comprar um ativo físico se este irá aumentar o benefício líquido dos proprietários da empresa, ou seja, o lucro líquido aumentará somente se a taxa esperada de retorno, ou rendimento do ativo, exceder a taxa de juros. Em relação à maximização do valor de mercado, destacam que vale a pena comprar um ativo se este aumentar o valor do patrimônio líquido dos proprietários, ou seja, se acrescenta mais ao valor de mercado da empresa do que os custos de aquisição. Desta forma, em suma, Modigliani e Miller (1958) defendem que são as decisões de investimento que maximizam o valor das organizações, independentemente das fontes de recursos das empresas, sejam elas de capital próprio ou de terceiros.

Em seguida, Modigliani e Miller (1963) trazem uma revisão de seu estudo seminal de 1958, em que relatam uma nova abordagem que considera os benefícios fiscais da dívida. Mais precisamente, mencionam que existe um ganho quando é realizado alavancagem financeira, uma vez que os juros destas operações são reconhecidos contabilmente como despesas, descontando assim dos lucros e, por consequência, reduzindo os tributos a recolher sobre o resultado da organização, o que torna o endividamento de terceiros menos oneroso.

Porém, destca-se que, apesar da existência dos impostos como vantagem para a dívida, não significa necessariamente que as corporações devem sempre utilizar o montante máximo de financiamento em sua estrutura de capital. Assim, as organizações precisam conciliar os impactos da dívida, propostos pela teoria static trade-off, a fim de alcançar o nível de endividamento ideal que proporcionará maximização do valor as firmas, que são dimensionados principalmente pelos custos de falência e benefícios fiscais da dívida. Tais preceitos da teoria static trade-off advém de inúmeras contribuições no decorrer dos anos de 1963 até a sua consolidação em 1984, com Myers (1984)

Posteriormente, Myers e Majluf (1984) destacaram entendimento sobre a hierarquia de recursos, ou teoria pecking-order, que baseia-se na utilização de capital para investimentos através de uma escala, onde primeiramente tem-se por finalidade utilizar os fundos gerados 
internamente por meio de lucros retidos, em segundo plano as empresas devem buscar recursos através de financiamentos com terceiros e, num terceiro momento, deve-se captar recursos por meio de emissão de ações.

Em suma, o modelo desenvolvido por Myers e Majluf (1984) sugere explicações para diversos aspectos do comportamento de financiamento corporativo, com destaque a tendência de confiar em fontes internas e a preferir dívida em contraponto à emissão de capital caso o financiamento externo for necessário. Além disso, cabe destaque, com estas duas variáveis de fontes de capitais - interna e externa -, que não há para a teoria pecking-order uma estruturaalvo ideal a ser seguida, mas a combinação hierárquica que permite a otimização dos recursos.

Empiricamente, Titman e Wessels (1988) buscaram compreender acerca dos determinantes da estrutura de capital analisando o poder explicativo de algumas das teorias existentes, que majoritariamente sugerem as empresas devendo mensurar propriedades que determinam os custos das dívidas e seus benefícios associados. Logo, detectaram através da discussão os atributos vinculados as teorias de estrutura de capital que podem afetar a maneira de endividamento das companhias, no caso norte-americanas. Esses atributos são, conforme achados, valor (tipo) dos ativos, benefícios fiscais da dívida, crescimento, singularidade, tamanho, volatilidade dos lucros e rentabilidade.

Posteriormente, Rajan e Zingales (1995) averiguaram os determinantes da estrutura de capital das organizações de capital aberto de países considerados potências mundiais, sendo elas: Alemanha, Canadá, Estados Unidos, França, Japão, Itália e Reino Unido. A amostragem foi composta no total por 2.583 empresas dos 7 países analisados e o período estudado foi composto para os anos de 1987 a 1991. Concluíram que a alavancagem empresarial é parecida nos países desenvolvidos analisados. Ademais, destacaram que o nível de endividamento é relacionado negativamente com valor de mercado e contábil, tamanho e lucratividade e positivamente com a tangibilidade.

Sunder e Myers (1999) testaram modelos tradicionais de estrutura de capital contra um modelo de hierarquia de financiamento das empresas. A amostragem abrangeu 157 empresas com informações sucessivas de 1971 até 1989. Fazendo contraponto entre pecking order theory e trade-off theory, os autores concluíram que a pecking order, na amostragem analisada, proporcionou majoridade no poder explicativo em uma série de tempo comparativamente a trade-off. Ademais, analisando empresas de capital aberto no Brasil, Perobelli e Famá (2001) verificaram quais seriam os fatores indutores do endividamento das empresas. A amostra final foi composta de 165 empresas de capital aberto, sendo os dados coletados no banco Economática ${ }^{\circledR}$. Os achados apontam que, no Brasil, o endividamento e os atributos tamanho, crescimento e lucratividade são negativamente associados

Com estudo voltado a países da América Latina, Perobelli e Famá (2003) analisaram no mercado latino-americano quais seriam os fatores explicativos do endividamento das corporações de capital aberto, representado pelos países Argentina, Chile e México. Ao analisarem os dados, verificou-se diferentes resultados para cada um dos países analisados, sendo que, na Argentina apenas o atributo lucratividade mostrou-se relacionada com o endividamento; no Chile, os atributos significantes foram tamanho, lucratividade e estrutura de ativos; e, no México, com exceção ao atributo estrutura de ativos, todos os demais apontaram conexão com o grau de endividamento das empresas (ou seja, crescimento, singularidade, tamanho, volatilidade dos resultados, lucratividade e benefícios fiscais).

Com foco em empresas de capital aberto do agronegócio brasileiro, Bressan et al. (2009) identificaram os determinantes da estrutura de capital destas organizações. A amostra foi composta por 26 empresas, sendo os dados coletados no banco de dados da Economática ${ }^{\circledR}$. 
Com base no modelo de regressão com dados em painel, os achados indicaram que as variáveis tangibildiade dos ativos, oportunidade de crescimento, tamanho e lucratividade foram estatisticamente significantes e, assim, podem ser interpretadas como fatores determinantes da estrutura de capital das empresas do setor de agronegócio brasileiro.

Correa, Basso e Nakamura (2013) examinaram o nível de endividamento das maiores empresas brasileiras, sendo a amostragem de 389 organizações, testando à aderência dos potenciais determinantes as teorias pecking order e trade-off. Como resultados, destaca-se a relação negativa entre endividamento com rentabilidade e grau de tangibilidade dos ativos e, em contrapartida, relação positiva do endividamento com o risco. Além disso, a análise mostrou baixa velocidade do processo de ajuste da estrutura de capital em direção ao nível-alvo, confirmando o viés com base na teoria pecking order.

\subsection{Folga Financeira}

Conceitualmente, conforme Nohria e Gulati (1996), entende-se por folga o volume de recursos em posse de uma organização que supera o mínimo necessário a fím de alcançar determinado nível de produção organizacional. Desta forma, o referido conceito é amplo, abrangendo questões como capacidade ociosa de empregados, de maquinário, custos e despesas desnecessárias, entre outras. Especificamente acerca da folga financeira, Campos e Nakamura (2015) defendem que esta é uma das formas de se criar forma organizacional, geralmente distinguida entre dois fatores: a) liquidez, sendo a folga financeira de curto prazo, admitida por ativos circulantes em excesso mantidos pela organização; e, b) poder de empréstimos, dimensionada como folga financeira de longo prazo e caracterizada como a capacidade da empresa de emitir dívida quando necessário.

Neste sentido, estudos mostraram a folga financeira como fator intrínseco às decisões corporativas. Singh (1986) menciona que este fator pode ser considerado moderador dos efeitos das capacidades e oportunidades nas decisões dos gestores na busca por novas alianças. Para Sharfman et al. (1988), a folga financeira pode ser distinta no que diz respeito ao critério utilizado para sua implantação. No cerne de desenvolvimento de produtos, a folga financeira tem-se mostrado fundamental, uma vez que é necessária a utilização de recursos para tanto, visto ainda que em se tratando de produtos de alta tecnologia, o processo pode ser longo, complexo e custoso (MISHINA; POLLOCK; PORAC, 2004).

Em outro prisma também contundente sobre a folga, George (2005) relata que esta é usada para estabilizar as operações da empresa, absorvendo o excesso de recursos durante o período de crescimento e permitindo que as empresas mantenham suas aspirações e compromissos durante períodos de crises. Desta forma, a folga pode absorver impactos no que tange a adaptar-se com êxito às pressões para mudança na política, bem como a fim de iniciar transformações na estratégia. Este duplo papel exercido pela folga a torna um mecanismo para influência no desempenho das empresas.

Conduto, Kim, Kim e Lee (2008) destacam que interesses internos podem resultar em diferentes preferências para a alocação de recursos de folga. Negativamente, exibindo a folga como uma fonte de problemas de agência, os teóricos desta vertente argumentam que a folga gera ineficiências, desencorajam os gerentes na tomada de decisões por criar comodismo e, consequentemente, tende a piorar o desempenho da organização. Positivamente, destacam que a folga financeira fornece às empresas autonomia, possuindo recursos necessários para explorar novas soluções e oportunidades, ou seja, as organizações têm recursos para experimentação em pesquisa e desenvolvimento que podem gerar resultados no futuro. 
Em sentido similar, Bradley, Shepherd e Wiklund (2011) trazem vieses tantos positivos quanto negativos quando se opera com folga financeira. Neste contexto, a folga financeira possui várias funções chaves, como blindar a empresa de variações internas e externas, reduzir conflitos intra-organizacional por meio do fornecimento de recursos para uma ampla variedade de projetos e, permite ainda, que as empresas experimentem mudanças organizacionais e inovações. Contudo, a folga pode também trazer resultados negativos, uma vez que tem sido associada, quando em níveis demasiadamente elevados, com a ineficiência na gestão por meio de investimentos em projetos que não aumentam o valor do acionista, a falta de ambição e o descasamento estratégico com o meio ambiente.

Empiricamente, diversos estudos acerca do assunto foram desenvolvidos, como o de Graham e Harvey (2001) que realizaram um levantamento sobre o custo, orçamento e estrutura de capital das empresas junto a 392 Chefes Financeiros (CFOs). Seus achados constataram que maiores empresas dependem fortemente de técnicas de valor presente e do modelo de precificação dos ativos, enquanto que pequenas organizações têm a propensão de utilizar o critério de retorno. Mais importante ainda, foi identificado que as organizações se preocupam com a flexibilidade financeira na busca pelo endividamento e recente valorização do preço das ações quando da emissão de capital próprio.

Daniel et al. (2004) realizaram uma pesquisa que mostrou várias relações entre folga de recursos e sua influencia no desempenho corporativo. Para tanto, foi realizada uma meta-análise com uma amostra de 66 estudos desenvolvidos em contextos diferentes, mas com metodologias de medição similares. Os resultados mostraram evidências majoritárias de haver relação positiva entre os três tipos de folga (disponível, recuperável e potencial) e desempenho corporativo. A análise também constatou que os estudos que empregam medidas de folga defasadas não mostraram uma relação forte para com a performance das empresas.

No estudo de Campos e Nakamura (2013) a folga financeira é dimensionada como variável de longo prazo numa perspectiva de endividamento relativo. A amostra é composta por empresas americanas de 65 setores diferentes no período de 1990 a 2009. Os resultados mostram, com base nas variáveis tradicionais de estrutura de capital, que a capacidade para se avaliar a folga financeira é fundamental. Desta forma, reitera-se que os resultados são robustos quando avaliados por endividamento contábil ou a valor de mercado.

Por fim, cabe destacar que dimensionar a folga financeira como determinante da estrutura de capital é plausível, visto que as teorias existentes consideram este fator. Mais especificamente, na ausência de oportunidades de investimentos, espera-se que as empresas mantenham lucros e acumulem solidez (folga) financeira com o intuito de evitar o financiamento externo no futuro (RAO, 2013), quando as oportunidades de crescimento surgirem, o que seria condizente com a teoria de pecking-order. De forma similar, em estudo com foco em alianças estratégicas, Zambuto, Lo Nigro e O'Brien (2017) sugerem que organizações com elevadas disponibilidades financeiras possuem baixa alavancagem, facilitando a consolidação de alianças. Além disso, quando gerentes enfrentam restrições para o acesso ao financiamento da dívida no ambiente, a função estabilizadora da folga financeira pode ser especialmente valiosa (VANACKER; COLLEWAERT; ZAHRA, 2017). Logo, é natural prever que a folga financeira é um potencial determinante da estrutura de capital corporativa, como será metodologicamente aplicado nesta pesquisa ao setor de alimentos. 


\section{Procedimentos Metodológicos}

Para analisar a influência da folga financeira na estrutura de capital das empresas de alimentos brasileiras, chilenas e mexicanas, considerando o endividamento geral, de curto prazo e de longo prazo, desenvolveu-se estudo descritivo, documental e de abordagem quantitativa. Mais precisamente, a característica descritiva pode ser observada uma vez que se observa variáveis sem manipula-las. Os procedimentos metodológicos tiveram caráter documental, visto que a análise baseia-se em demonstrações financeiras publicadas pelas empresas estudadas no período de 2009 a 2013 disponíveis na base de dados Thomson ${ }^{\circledR}$. Por fim, a abordagem do problema é quantitativa por tratar-se de estudo empírico, no qual foram utilizados métodos estatísticos durante a coleta, tratamento e análise dos dados.

\subsection{População e Amostra da pesquisa}

Para o desenvolvimento dessa pesquisa, a população foi composta por todas as empresas de capital aberto dos países Brasil, Chile e México, classificadas no setor de alimentos da Base de dados Thomson $\circledR$. Mais precisamente, a amostra foi composta por empresas do segmento de alimentos processados, utilizando o código internacional SIC (Standard Industrial Classification), conforme descrito na Tabela 1 abaixo exposta:

Tabela 1 - Amostra da pesquisa conforme o código SIC

\begin{tabular}{c|c}
\hline SIC & Descrição \\
\hline 201 & Carnes \\
\hline 202 & Laticínios \\
\hline 203 & Conservas \\
\hline 204 & Cereais e legumes \\
\hline 205 & Padaria \\
\hline 206 & Açúcares e confeitaria \\
\hline
\end{tabular}

Fonte: dados da pesquisa.

Ademais, foram eliminadas as empresas que não continham informações sobre os dados para cálculo das variáveis, bem como aquelas com informações consideradas outliers por estarem mais de três desvios-padrão longe da média, contemplando amostra final de 29 empresas dos três países, sendo especificamente 9 brasileiras, 11 chilenas e 9 mexicanas. Os dados destas empresas, quanto ao endividamento geral, de curto e de longo prazo e das demais variáveis tiveram aspecto primário e sua coleta ocorreu em novembro de 2014.

\subsection{Procedimentos para coleta e análise dos dados}

Para elaboração do instrumento de pesquisa desenvolveu-se o constructo. As variáveis utilizadas neste estudo foram levantadas conforme a literatura pesquisada e são demonstradas no Quadro 1.

A escolha dos indicadores descritos no Quadro 1 está fundamentada pelos autores mencionados, sendo que tais estudos obtiveram êxito com a escolha dessas variáveis em suas pesquisas. Os dados utilizados foram extraídos do sítio eletrônico da Thomson ONE Banker, na base de dados Thomson Financial e Worldscope, com período de 2009 a 2013. 
Quadro 1 - Variáveis desse estudo

\begin{tabular}{|c|c|c|c|}
\hline $\begin{array}{c}\text { Variáveis } \\
\text { dependentes }\end{array}$ & Descrição & Medição & Autores \\
\hline C_DEBT & $\begin{array}{l}\text { Endividamento } \\
\text { de curto prazo }\end{array}$ & Passivo Circulante / Ativo Total & Bastos e Nakamura (2009). \\
\hline L_DEBT & $\begin{array}{l}\text { Endividamento de } \\
\text { longo prazo }\end{array}$ & $\begin{array}{l}\text { Passivo não Circulante / Ativo } \\
\text { Total }\end{array}$ & Bastos e Nakamura (2009). \\
\hline T_DEBT & Endividamento total & $\begin{array}{l}\text { (Passivo Circulante }+ \text { Passivo } \\
\text { não Circulante) / Ativo Total }\end{array}$ & $\begin{array}{l}\text { Titman e Wessels (1988); } \\
\text { Bastos e Nakamura (2009). }\end{array}$ \\
\hline $\begin{array}{c}\text { Variáveis } \\
\text { independentes }\end{array}$ & Descrição & Medição & Autores \\
\hline SLACK & Folga Financeira & $\begin{array}{c}\text { (Ativo circulante }- \text { Estoque }) / \\
\text { Passivo circulante }\end{array}$ & Campos e Nakamura (2013). \\
\hline PROFIT & Rentabilidade & EBITDA / Ativo Total & $\begin{array}{c}\text { Costa e Correia (2007); } \\
\text { Bastos e Nakamura (2009). }\end{array}$ \\
\hline GROW & Crescimento & $\begin{array}{c}\text { (Ativo total } \mathrm{t}-\text { ativo total } \mathrm{t}-1) / \\
\text { Total dos ativos } \mathrm{t}-1\end{array}$ & Titman e Wessels (1988). \\
\hline TANG & Tangibilidade & Ativo Imobilizado / Ativo Total & Costa e Correia (2007). \\
\hline SIZE & Tamanho & Ln Ativo Total & $\begin{array}{l}\text { Titman e Wessels (1988); } \\
\text { Costa e Correia (2007). }\end{array}$ \\
\hline
\end{tabular}

Fonte: dados da pesquisa.

Para análise dos dados foi utilizado o método de regressão com dados em painel (panel data) a fim de identificar a influência da folga financeira na estrutura de capital das empresas de alimentos brasileiras, chilenas e mexicanas. Desta forma, os modelos operacionalizados para cada um dos três países individualmente são apresentados abaixo:

$$
\begin{aligned}
& C_{-} D E B T_{i t}=\alpha+\beta_{1} \text { SLACK }_{i t}+\beta_{2} \text { PROFIT }_{i t}+\beta_{3} \text { GROW }_{i t}+\beta_{4} \text { TANG }_{i t}+\beta_{5} \text { SIZE }_{i t}+\mu \\
& L_{-} D E B T_{i t}=\alpha+\beta_{1} \text { SLACK }_{i t}+\beta_{2} \text { PROFIT }_{i t}+\beta_{3} \text { GROW }_{i t}+\beta_{4} \text { TANG }_{i t}+\beta_{5} \text { SIZE }_{i t}+\mu \\
& T_{-} D E B T_{i t}=\alpha+\beta_{1} \text { SLACK }_{i t}+\beta_{2} \text { PROFIT }_{i t}+\beta_{3} \text { GROW }_{i t}+\beta_{4} \text { TANG }_{i t}+\beta_{5} \text { SIZE }_{i t}+\mu
\end{aligned}
$$

Mais precisamente, a análise de cada modelo foi composta pela resposta ao objetivo da pesquisa, assim, além de uma perspectiva do endividamento total, também foi observada a influência da folga financeira com o endividamento de curto prazo e de longo prazo. Os dados foram tratados por meio do software STATA 12, em que primeiramente realizaram-se os testes necessários para atendimento dos pressupostos da regressão, incluindo normalidade, homocedasticidade, multicolinearidade e autocorrelação dos resíduos, para posterior consecução do modelo em questão.

\section{Descrição e Análise dos Dados}

Posterior à realização dos pressupostos que garantem a aplicabilidade da técnica estatística de regressão com dados em painel, foram aplicados os testes para definição do método a ser utilizado, ou seja, se seria pooling, efeitos fixos ou efeitos aleatórios. Num primeiro momento, o teste Chow foi utilizado para verificar a igualdade (pooling) ou diferença (efeitos fixos) para todas as croos-sections. Em seguida, o teste LM de Breusch-Pagan foi 
realizado para verificar se a variância dos resíduos que mostram as diferenças individuais é igual (pooling) ou diferente (efeitos aleatórios) de zero. E, ao final, foi feito o teste de Hausman com o intuito de comparação dos resultados dos modelos de efeitos fixos com o de efeitos aleatórios. Desta forma, identifica-se qual dos modelos se ajusta melhor aos dados, aplicandoo posteriormente. Com base nisto, apresentam-se os resultados na Tabela 2.

Conforme Tabela 2, os testes Chow, LM de Breush-Pagan e Hausman indicaram que oito dos nove modelos são realizados por efeitos fixos (exceto o de endividamento de longo prazo no Brasil, sendo este também o único não significativo). Em referência aos coeficientes de determinação $\mathrm{R}^{2}$, ou seja, o poder explicativo dos modelos operacionalizados, para as empresas brasileiras o valor apontou 0,641 (C_DEBT) e 0,499 (T_DEBT) e para o modelo L_DEBT não apresentou significância, o que inviabiliza sua análise. Mais precisamente, estes dados sugerem que as variáveis independentes de estudo são responsáveis por $64,1 \%$ da variação do endividamento de curto prazo e 49,9\% do endividamento total no Brasil.

Nesta mesma linha, observou-se que para as empresas chilenas os três modelos foram significativos, sendo estes com poder explicativo de 58,3\% para a variação do endividamento de curto prazo, 27,8\% para o endividamento de longo prazo e 63,6\% para o modelo de endividamento total. Quanto às empresas mexicanas, por sua vez, os três modelos operacionalizados também foram significativos, sendo que o poder explicativo apresentado foi de $54,6 \%$ para o endividamento de curto prazo, $60,5 \%$ para o endividamento de longo prazo e $36,0 \%$ para o endividamento total. Em suma, estes resultados mostram relevante explicação das variáveis independentes sobre os níveis de endividamento estudados, inclusive em todos os cenários observados, o que maximiza a relevância dos achados apresentados.

Em referência a análise individual por país e por variável, observou-se que no Brasil a folga financeira (SLACK) apresentou relação negativa em todos os três níveis de endividamento, contudo, no que tange ao endividamento de longo prazo, o modelo não apresentou significância, o que não permite inferências. Em relação ao endividamento de curto prazo e total, devido à existência de relação negativa e significante, pode-se inferir que no Brasil empresas do setor de alimentos com maior folga financeira apresentam menor endividamento. Este fato é consonante com a assertiva de Zambuto, Lo Nigro e O'Brien (2017) de que empresas com disponibilidades financeiras abundantes possuem menor alavancagem. Além disso, a teoria de estrutura de capital pecking-order pode fornecer subsídios a tais resultados, visto que empresas com alta solidez financeira tendem a possuir retenção de resultados, evitando o endividamento quando a possibilidade de investimento futuro surgir (RAO, 2013).

Em relação à rentabilidade, para todos os níveis de endividamentos, ou seja, de curto prazo, de longo prazo e total, apesar de negativa, a variável não apresentou significância, o que não permite inferir conclusão acerca desta relação, visto que a rentabilidade não se demonstrou determinante do endividamento de empresas alimentícias brasileiras. Ademais, no que tange a variável crescimento da empresa, esta apresentou sinal negativo em relação ao endividamento de curto prazo e de longo prazo, porém em ambos os casos não foi significativa. Entretanto, tem-se como principal achado neste sentido a ocorrência de significância negativa entre crescimento da empresa e o endividamento total, remetendo a conclusão de que empresas com menor crescimento possuem endividamento total inferior. Tal fato corrobora com os achados de Perobelli e Famá (2001) em seu estudo com empresas brasileiras. De fato, é natural pressupor que empresas cujo nível de atividade esteja estabilizado no mercado, busquem capital de terceiros em menor grau, mediante baixa necessidade de aquisições, principalmente de novos ativos fixos que demandam alto volume de recursos financeiros. 
Tabela 2 - Resultados dos modelos de regressão em painel

\begin{tabular}{|c|c|c|c|c|c|c|}
\hline \multirow{4}{*}{ Variáveis } & \multicolumn{6}{|c|}{ BRASIL } \\
\hline & \multirow{2}{*}{\multicolumn{2}{|c|}{$\begin{array}{l}\text { EFEITOS FIXOS } \\
\text { (1) Endividamento } \\
\text { Curto Prazo }\end{array}$}} & \multicolumn{2}{|c|}{ POLS } & \multicolumn{2}{|c|}{ EFEITOS FIXOS } \\
\hline & & & $\begin{array}{l}\text { (2) Endi } \\
\text { Long }\end{array}$ & $\begin{array}{l}\text { mento } \\
\text { azo }\end{array}$ & \multicolumn{2}{|c|}{$\begin{array}{c}\text { (3) Endividamento } \\
\text { Total }\end{array}$} \\
\hline & Coefic. & Sig. & Coefic. & Sig. & Coefic. & Sig. \\
\hline SLACK & -0.288 & $0.008^{*}$ & -0.026 & 0.435 & -0.29 & $0.012 *$ \\
\hline PROFIT & -0.309 & 0.084 & -0.034 & 0.529 & -0.357 & 0.065 \\
\hline GROW & -0.218 & 0.059 & -0.01 & 0.763 & -0.249 & $0.045^{*}$ \\
\hline TANG & -0.37 & 0.061 & -0.015 & 0.878 & -0.416 & 0.052 \\
\hline SIZE & -0.056 & $0.010 *$ & 0.001 & 0.973 & -0.002 & 0.937 \\
\hline $\begin{array}{c}\text { Sig. Model. } \\
\text { R }^{2} \\
\text { LM de Breusch-Pagan } \\
\text { Teste de Chow } \\
\text { Teste de Hausman } \\
\end{array}$ & \multicolumn{2}{|c|}{$\begin{array}{l}\text { Sig X } X^{2} 0,0000^{*} \\
\text { Sig. F 0,0000* } \\
\text { Sig. X } X^{2} 0,0000^{*}\end{array}$} & $\begin{array}{r}0 \\
0 \\
\text { Sig X }\end{array}$ & 000 & \multicolumn{2}{|c|}{$\begin{array}{c}0,499 \\
\text { Sig } X^{2} 0,0000^{*} \\
\text { Sig. F } 0,0000^{*} \\
\text { Sig. } X^{2} 0,0000^{*}\end{array}$} \\
\hline $\mathrm{N}^{\circ}$ obs. & & & & & & \\
\hline \multirow{4}{*}{ Variáveis } & \multicolumn{6}{|c|}{ CHILE } \\
\hline & \multirow{2}{*}{\multicolumn{2}{|c|}{$\begin{array}{l}\text { EFEITOS FIXOS } \\
\text { (1) Endividamento } \\
\text { Curto Prazo } \\
\end{array}$}} & \multirow{2}{*}{\multicolumn{2}{|c|}{$\begin{array}{c}\text { EFEITOS FIXOS } \\
\text { (2) Endividamento } \\
\text { Longo Prazo } \\
\end{array}$}} & \multirow{2}{*}{\multicolumn{2}{|c|}{$\begin{array}{c}\text { EFEITOS FIXOS } \\
\text { (3) Endividamento } \\
\text { Total } \\
\end{array}$}} \\
\hline & & & & & & \\
\hline & Coefic. & Sig. & Coefic. & Sig. & Coefic. & Sig. \\
\hline SLACK & -0.158 & $0.000^{*}$ & 0.088 & $0.002 *$ & -0.062 & 0.286 \\
\hline PROFIT & -0.221 & 0.123 & 0.322 & 0.132 & 0.166 & $0.008 *$ \\
\hline GROW & -0.052 & 0.234 & -0.031 & 0.592 & -0.08 & 0.351 \\
\hline TANG & -0.464 & $0.000^{*}$ & 0.096 & 0.475 & -0.257 & 0.104 \\
\hline SIZE & -0.004 & 0.866 & 0.119 & $0.016^{*}$ & 0.16 & $0.026^{*}$ \\
\hline $\begin{array}{c}\text { Sig. Model. } \\
\text { R }^{2} \\
\text { LM de Breusch-Pagan } \\
\text { Teste de Chow } \\
\text { Teste de Hausman } \\
\end{array}$ & \multicolumn{2}{|c|}{$\begin{array}{c}0,000^{*} \\
0,583 \\
\text { Sig } \mathrm{X}^{2} 0,0000^{*} \\
\text { Sig. F } 0,0000^{*} \\
\text { Sig. } \mathrm{X}^{2} 0,0000^{*} \\
\end{array}$} & \multicolumn{2}{|c|}{$\begin{array}{c}0,022^{*} \\
0,278 \\
\text { Sig } \mathrm{X}^{2} 0,0000^{*} \\
\text { Sig. F } 0,0000^{*} \\
\text { Sig. } \mathrm{X}^{2} 0,0000^{*} \\
\end{array}$} & \multicolumn{2}{|c|}{$\begin{array}{c}0,636 \\
\text { Sig } X^{2} 0,0000^{*} \\
\text { Sig. F } 0,0000^{*} \\
\text { Sig. } X^{2} 0,0000^{*}\end{array}$} \\
\hline $\mathrm{N}^{\circ}$ obs. & & & & & \\
\hline \multirow{4}{*}{ Variáveis } & \multicolumn{6}{|c|}{ MÉXICO } \\
\hline & \multirow{2}{*}{\multicolumn{2}{|c|}{$\begin{array}{l}\text { EFEITOS FIXOS } \\
\text { (1) Endividamento } \\
\text { Curto Prazo }\end{array}$}} & \multirow{2}{*}{\multicolumn{2}{|c|}{$\begin{array}{c}\text { EFEITOS FIXOS } \\
\text { (2) Endividamento } \\
\text { Longo Prazo }\end{array}$}} & \multirow{2}{*}{\multicolumn{2}{|c|}{$\begin{array}{c}\text { EFEITOS FIXOS } \\
\text { (3) Endividamento } \\
\text { Total }\end{array}$}} \\
\hline & & & & & & \\
\hline & Coefic. & Sig. & Coefic. & Sig. & Coefic. & Sig. \\
\hline SLACK & -0.091 & $0.000 *$ & 0.074 & $0.000 *$ & -0.021 & 0.244 \\
\hline PROFIT & 0.092 & 0.645 & -0.395 & 0.074 & -0.356 & 0.082 \\
\hline GROW & -0.022 & 0.685 & -0.053 & 0.393 & -0.082 & 0.149 \\
\hline TANG & -0.571 & $0.026^{*}$ & 0.369 & 0.049 & -0.055 & 0.765 \\
\hline SIZE & -0.04 & 0.278 & 0.063 & $0.002 *$ & 0.035 & 0.106 \\
\hline $\begin{array}{c}\text { Sig. Model. } \\
\text { R }^{2} \\
\text { LM de Breusch-Pagan } \\
\text { Teste de Chow } \\
\text { Teste de Hausman } \\
\end{array}$ & $\begin{array}{r}0, \\
0, \\
\text { Sig } X^{2} \\
\text { Sig. F } \\
\text { Sig. } \mathrm{X}^{2} \\
\end{array}$ & $\begin{array}{l}000 * \\
000 * \\
000 *\end{array}$ & $\begin{array}{r}0, \\
0 \\
\text { Sig } \mathrm{X}^{2} \\
\text { Sig. F } \\
\text { Sig. } \mathrm{X} \\
\end{array}$ & $\begin{array}{l}00 * \\
00 * \\
00 *\end{array}$ & $\begin{array}{r}0, \\
0 \\
\text { Sig } \mathrm{X}^{2} \\
\text { Sig. F } \\
\text { Sig. X } \\
\end{array}$ & $\begin{array}{l}000 * \\
000^{*} \\
000^{*}\end{array}$ \\
\hline $\mathrm{N}^{\circ}$ obs. & & & & & & \\
\hline
\end{tabular}

*nível de significância de 5\%.

Fonte: dados da pesquisa 
No que diz respeito a variável tangibilidade, tanto em relação ao endividamento de curto prazo, de longo prazo e total, os coeficientes auferidos são negativos, contudo, em todos os casos não significativos. Desta forma, não se pode afirmar que tal relação é consistente, visto que em nenhum dos níveis de endividamento supracitados a variável tangibilidade apresentou significância para análise junto as empresas brasileiras. Por fim, ainda no contexto brasileiro, a variável tamanho apresentou relação negativa com os endividamentos de curto prazo e total, enquanto teve fraca relação positiva com o endividamento de longo prazo. Todavia, o maior achado neste cenário é a relação negativa entre o tamanho e o endividamento de curto prazo, uma vez que foi a única que apresentou significância ao nível de 5\%. Assim, tal fato permite constatar que para as empresas brasileiras analisadas, quanto maior o tamanho, menor tende a ser o endividamento de curto prazo. Na literatura, foi encontrado suporte para tal relação nos trabalhos de Rajan e Zingales (1995) e Perobelli e Famá (2001) que associaram negativamente o tamanho da empresa com o endividamento.

Em relação ao Chile, a folga financeira apresentou significância com o endividamento das empresas em dois dos três níveis analisados (no caso, de curto prazo e de longo prazo). Todavia, é importante destacar que a referida variável apresentou relações diferentes entre os níveis de endividamento, sendo negativamente relacionada com a dívida de curto prazo e total (esta última insignificante) e positivamente com a dívida de longo prazo. Neste contexto, uma das relações apresentadas remete que em empresas chilenas do setor de alimentos, quanto maior a folga financeira, menor é o endividamento das empresas no curto prazo. Em contrapartida, este fato não se confirmou atrelado ao endividamento que longo prazo, que apresentou o sentido de que quanto maior a folga financeira, maior é o referido nível de endividamento. A consistência dos modelos ora apresentados também foi encontrada por Campos e Nakamura (2013), relatando que a folga financeira apresenta poder explicativo na estrutura de capital das empresas.

Teoricamente, ainda em referência a folga financeira, a relação negativa observada entre esta variável para com o endividamento de curto prazo de empresas chilenas pode ser, assim como no cenário brasileiro, compreendida por meio da teoria pecking-order. Mais precisamente, de acordo com Denis (2011), diante do real dispêndio existente nas finanças externas, as organizações passam a ter incentivos nítidos de acumular recursos financeiros com o intuito de construir folga, sendo estes advindos da geração interna, evitando consequências adversas como choques nos lucros e/ou em oportunidades de investimentos. Em contrapartida, a relação positiva entre folga financeira e endividamento de longo prazo é inconsistente com a assertiva anterior, mas pode ser compreendida como uma forma das empresas que não conseguem gerar recursos suficientes internamente buscarem a segurança advinda da folga em dívida de longo prazo, quando o dispêndio financeiro ocorrerá apenas em períodos posteriores.

Notadamente, a folga pode ser utilizada por gestores para estabilizar as operações das organizações (GEORGE, 2005), principalmente em períodos de recessão. Além disso, sob o prisma positivo da folga financeira, Kim, Kim e Lee (2008) destacam que esta possui potencial de fornecer as empresas autonomia, visto a existência de recursos existentes a todo o momento para explorar novas soluções e oportunidades. Assim, pressupõe-se que às empresas que não conseguem gerar recursos suficientes internamente a fim de honrar todos seus compromissos e, ainda, criar folga financeira, visando usufruir dos benefícios desta, optam por aumentar seu endividamento de longo prazo, cujo desembolso se dará em períodos subsequentes. A consecução de folga no presente via capital de terceiros de longo prazo pode garantir as organizações recursos necessários em períodos cujo crédito de terceiros se torne mais difícil, como é o caso de crises econômicas. De fato, Vanacker, Collewaert e Zahra (2017) mencionam que ter recursos em caixa, quando da existência de restrições financeiras no meio ambiente, 
pode aliviar o risco potencial de subinvestimentos e restaurar a flexibilidade estratégica de uma empresa. Assim, tais assertivas caracterizam as diferenças encontradas para o endividamento de curto prazo comparativamente ao endividamento de longo prazo.

Ademais, quanto a variável rentabilidade, foi observada no cenário chileno relação negativa com o endividamento de curto prazo e relação positiva com o endividamento de longo prazo e total. Todavia, dos três modelos citados, apenas houve significância da variável independente, no caso a rentabilidade, com o endividamento total (de forma positiva). Tais achados sugerem que empresas alimentícias chilenas que possuem maior rentabilidade operam com o endividamento total mais elevado. Estes resultados divergem com o observado por Correa, Basso e Nakamura (2013) no contexto brasileiro, que encontraram relação negativa entre rentabilidade e endividamento (CORREA; BASSO; NAKAMURA, 2013), sendo inconsistente também com a teoria pecking-order, que defende uma hierarquia de recursos, em que o capital próprio (interno) seria menos custoso do que o capital de terceiros, maximizando, por consequência, a rentabilidade corporativa.

Ainda em referência ao acima descrito, destaca-se que a relação positiva entre rentabilidade e endividamento é defensável. A teoria trade-off assevera que as organizações devem conciliar os custos e benefícios da dívida, perpassando estes principalmente pelo risco de falência e vantagens fiscais da dívida, respectivamente (MODIGLIANI; MILLER, 1963; MYERS, 1984). Logo, mesmo sendo operacionalizado modelo linear nesta pesquisa, empresas com rentabilidade superior apresentaram maior endividamento, conotando que os benefícios da dívida prolongam-se a patamares mais elevados de endividamento no Chile. Ademais, no que tange a variável crescimento da empresa, em todos os modelos apresentados foi constatado que a mesma está negativamente relacionada com os níveis de endividamento, o que, a princípio, remete que quanto maior o crescimento das empresas chilenas, menor é o endividamento. Contudo, nos três modelos a variável crescimento não apresentou significância com os níveis de endividamento analisados, o que conota a necessidade de um melhor poder de explicação para afirmar esta relação.

Quanto à tangibilidade, esta se apresentou relacionada negativamente e significativamente com o endividamento de curto prazo, o que permite afirmar que em empresas chilenas, quanto maior a tangibilidade, menor é o endividamento de curto prazo. Tal fato é amparado por Correa, Basso e Nakamura (2013) que também encontraram relação negativa entre a variável independente tangibilidade e o endividamento, porém, divergente do estudo de Rajan e Zingales (1995) que evidenciaram relação positiva entre ambas as variáveis em questão. Desta forma, é possível verificar que a tangibilidade e sua influência no endividamento é ambígua na literatura. Além disso, acerca dos achados desta pesquisa em específico, é entendível prever que a tangibilidade esteja inversamente relacionada com o endividamento de curto prazo, visto a não viabilidade de financiar ativos que gerarão fluxo de caixa no longo prazo com recursos a serem quitados no curto prazo. Por fim, cabe destacar adicionalmente acerca da variável tangibilidade que para a relação com o endividamento de longo prazo em empresas chilenas esta apresentou sinal positivo e para com o endividamento total tem-se sinal negativo, porém ambas não possuem significância, o que não permite inferir sobre o fenômeno observado.

Por fim, ainda nas empresas chilenas, a variável tamanho apresentou significância com o endividamento de longo prazo e o endividamento total, sendo a relação positiva. Neste caso, tem-se que para as empresas chilenas, quanto mais elevado o seu tamanho maior será o endividamento corporativo (de longo prazo e total). Tal resultado é contrário ao evidenciado no estudo de Rajan e Zingales (1995) e Perobelli e Famá (2001), todavia, pode ser explicado por 
prerrogativas teóricas, como assevera Tripathy e Asija (2017) de que grandes corporações operam com nível de endividamento mais elevado devido sua diversificação ampla e menor risco de falência, garantindo leque mais abundante de oportunidades de financiamento externo. Destaca-se ainda, no que tange ao tamanho influenciando o endividamento de curto prazo, que houve fraca relação negativa, porém, esta não apresentou significância e, assim, não possui potencial de explicar o endividamento de curto prazo em empresas chilenas.

Por fim, em análise do cenário mexicano, a folga financeira apresentou significância tanto no endividamento de curto prazo bem como no endividamento de longo prazo, porém, a relação é negativa com o primeiro (curto prazo) e positiva com o segundo (longo prazo), resultados estes iguais ao observado no contexto chileno. Mais precisamente, tais interpretações são dadas da forma que quanto maior a folga financeira, menor é o endividamento de curto prazo das empresas mexicanas e maior é a dívida de longo prazo das referidas organizações. Em referência ao endividamento total, apesar de negativa, a folga financeira não apresentou significância, não permitindo inferências neste nível de endividamento. Cabe destacar que as justificativas para tais achados são similares ao cenário chileno no que concerne esta variável de folga financeira, conforme descritas anteriormente.

Posteriormente, em referência a rentabilidade e ao crescimento das empresas, no México, em todos os níveis de endividamento, estas não apresentaram significância nos modelos operacionalizados. Desta forma, tem-se que tais variáveis não possuem potencial de explicar os níveis de endividamento das empresas mexicanas do setor de alimentos. A tangibilidade, por sua vez, mostrou-se significativa apenas quando relacionada negativamente com o endividamento de curto prazo, não havendo significância no endividamento de longo prazo e total. Neste contexto, o principal achado é de que quanto maior a tangibilidade das empresas mexicanas, menor é o endividamento de curto prazo. Tal relação é corroborada por Correa, Basso e Nakamura (2013) no cenário brasileiro.

A última variável independente analisada para as empresas mexicanas consiste no tamanho, que se mostrou positivamente e significativamente relacionado apenas com o endividamento de longo prazo, não havendo, assim, significância desta variável com o endividamento de curto prazo e total. Logo, tem-se que quanto maior o tamanho das empresas mexicanas analisadas, maior tende a ser o endividamento de longo prazo destas. Tal evidência não corrobora com os estudos de Rajan e Zingales (1995) e Perobelli e Famá (2001), que relataram a relação do tamanho com o endividamento de forma negativa, mas podem ser compreendidas pela assertiva teórica de Mouton e Smith (2016) de que a elevação do tamanho de uma organização possibilita a geração de fluxos de caixa mais estáveis, menores possibilidades de sofrimento financeiro, melhores ratings de crédito, etc., aprimorando, por consequência, a capacidade destas organizações de buscar empréstimos junto a terceiros.

No geral, percebe-se que há similaridades e distinções entre os fatores explicativos da estrutura de capital nas empresas do setor de alimentos do Brasil, Chile e México. Quanto à folga financeira, foco principal de pesquisa, é possível verificar que esta apresentou significância em seis dos nove modelos analisados, sendo dois para a amostra de cada país foco de estudo. Neste contexto, a relação entre folga financeira e endividamento se mostrou negativa e significante em quatro modelos, tendo como mais forte coeficiente o endividamento total em empresas brasileiras $(-0,290)$. Tal relação proporciona consistência, uma vez que, em geral, organizações que possuem quantidade mais abundante de recursos disponíveis tendem a necessitar menos de capital de terceiros, visto que estes recursos geralmente advêm da geração própria de capital.

Todavia, é importante destacar que tanto no cenário chileno como no mexicano a folga financeira apresentou relação positiva com o endividamento de longo prazo, com coeficientes 
de 0,088 no Chile e 0,074 no México. Explicação plausível para tal fenômeno consiste nos benefícios atrelados a folga financeira, que fazem com que empresas insuficientes de geração interna de recursos para honrar seus compromissos e, ainda, alocar recursos financeiros em folga, busquem a via endividamento de longo prazo, onde os desembolsos se darão em longo espaço de tempo. Logo, em suma, os resultados aqui auferidos mostram que a folga financeira tem relação com o endividamento de forma similar no Chile e México, enquanto no Brasil os achados convergem parcialmente. Por fim, quanto às demais variáveis estudadas, sendo elas rentabilidade, crescimento da empresa, tangibilidade e tamanho, constatou-se novamente que existem semelhanças mais próximas entre os achados vinculados ao Chile e México comparativamente ao cenário brasileiro.

\section{Conclusões e Recomendações}

Este estudo teve por objetivo examinar a influência da folga financeira na estrutura de capital das empresas de alimentos brasileiras, chilenas e mexicanas. A análise abrangeu o total de 29 empresas, sendo 9 brasileiras, 11 chilenas e 9 mexicanas, com período de análise de 2009 a 2013. Como foco principal, a folga financeira apresentou relação significante em seis dos nove modelos executados, sendo que destes, quatro apresentaram relação negativa e dois positiva com os níveis de endividamento analisados.

Mais especificamente, observou-se que nos três países estudados, a folga financeira diminui o endividamento de curto prazo das corporações, assim como no Brasil, especificamente, influencia também negativamente no endividamento total. De fato, conforme Rao (2013), organizações com excesso de recursos financeiros disponíveis tendem a apresentar baixo endividamento. Este aspecto pode ser explicado pela perspectiva da teoria de estrutura de capital pecking-order, que caracteriza a preferência de financiar as atividades corporativas com recursos próprios, visto que a assimetria de informação para com estes ser menor e, por conseguinte, o capital capturado apresentar custo mais acessível. Desta forma, organizações altamente rentáveis tendem a reter lucros, mesmo que em folga financeira, para não precisar de financiamento futuro quando da necessidade de ampliação de suas atividades.

Todavia, é imprescindível resaltar que nos contextos chilenos e mexicanos, a folga financeira está positivamente relacionada à dívida de longo prazo. Neste sentido, é de conhecimento na literatura que a folga financeira pode ser observada como maximizadora do desempenho corporativo, visto que, conforme Bradley, Shepherd e Wiklund (2011) esta possui, entre outros aspectos, potencial para que as empresas adotem mudanças organizacionais e inovações, buscando diferencial de mercado. Logo, é possível compreender que empresas insuficientes de geração interna de recursos a fim de honrar seus compromissos e, ainda, gerar folga financeira, busquem recursos de terceiros de longo prazo, com lacuna de pagamentos longevos, para usufruir dos benefícios da folga financeira, como a capacidade discricionária de alocar recursos em projetos oportunos que o mercado oferece.

Ademais, ressalta-se ainda que existem maiores semelhanças entre os determinantes da estrutura de capital em empresas chilenas e mexicanas, uma vez que estas apresentaram relação positiva da folga financeira com o endividamento de longo prazo, enquanto no Brasil tal fato não pode ser constatado, além de que nas variáveis significantes de tangibilidade e tamanho, a primeira (tangibilidade) afeta negativamente o endividamento de curto prazo de organizações do Chile e do México, enquanto a segunda (tamanho) está positivamente relacionada ao endividamento de longo prazo nas organizações dos referidos países, o que não ocorre no 
cenário brasileiro. Assim sendo, estes aspectos corroboram para maior semelhança dos achados em empresas chilenas e mexicanas comparativamente as brasileiras.

Em suma, os resultados desta pesquisa possuem potencial em compreender a forma como gestores dimensionam a folga financeira e, por consequência, seu impacto diversificado nos níveis de endividamento, haja vista que tais recursos em excesso advêm de fontes internas e/ou externas, interferindo na estrutura de capital corporativa. Mais importante ainda, consta em identificar que a folga financeira é um fator importante para explicar a forma como as organizações estruturam seu capital, notadamente, neste caso, de empresas do setor de alimentos do Brasil, Chile e México. De fato, conforme Zhong (2011), apesar da importância da folga financeira, a literatura ainda não dispõe de formulações consistentes a seu respeito (ZHONG,2011), o que impulsiona a realização de novos estudos, sobretudo em setores específicos da economia, para efeito de melhor comparabilidade dos achados, valorizando, portanto, a configuração desta pesquisa.

Contudo, cabe destacar que mesmo com contribuições para a literatura, esta pesquisa não pretende esgotar o assunto, haja vista a complexidade do fenômeno observado e as limitações inerentes a estudos deste tipo. Assim, destaca-se como limitação desta pesquisa primordialmente o número reduzido de empresas analisadas, o que gera volume de observações reduzidas, apesar de constar todas as empresas de capital aberto dos países analisados, minimizando, mas não extinguindo, a referida limitação. Por fim, como direcionamentos para trabalhos futuros, recomenda-se a realização de pesquisas com outros setores da economia, o que garante melhor comparabilidade entre as empresas, bem como a inserção de demais variáveis que possam explicar a forma como as organizações estruturam seu capital como, por exemplo, a idade da empresa, que impacta no estágio de maturidade da organização e, por consequência, na sua maneira de financiar as atividades.

\section{Referências}

ANGGONO, A. H.; PERTIWI, G. C. Optimal Capital Structure Analysis of Food and Beverages Sub-Sector Industry in Indonesia from 2008-2011: A Case Study. World Journal of Social Sciences, v. 13, n. 4, p. 212-227, 2013.

BASTOS, D. D.; NAKAMURA, W. T. Determinantes da estrutura de capital das companhias abertas no Brasil, México e Chile no período 2001-2006. Revista Contabilidade \& FinançasUSP, v. 20, n. 50, p. 75-94, 2009. http://dx.doi.org/10.1590/S1519-70772009000200006

BASTOS, D. D.; NAKAMURA, W. T.; BASSO, L. F. C. Determinantes da Estrutura de Capital das Companhias Abertas na América Latina: Um estudo empírico considerando fatores macroeconômicos e institucionais. RAM - Revista de Administração Mackenzie, v. 10, n. 6, p. 47-77, 2009. http://dx.doi.org/10.1590/S1678-69712009000600005

BENACHENHOU, A. Países Emergentes. Brasília: Fundação Alexandre de Gusmão. 2013.

BRADLEY, S. W.; SHEPHERD, D. A.; WIKLUND, J. The importance of slack for new organizations facing 'tough'environments. Journal of Management Studies, v. 48, n. 5, p. 1071-1097, 2011. doi:10.1111/j.1467-6486.2009.00906.x

BRESSAN, V. G. F.; BRESSAN, A. A.; BRAGA, M. J.; LIMA, J. E. de. Análise dos determinantes do endividamento das empresas de capital aberto do agronegócio 
brasileiro. Revista de Economia e Sociologia Rural - RESR, v. 47, n. 1, p. 89-122, 2009. http://dx.doi.org/10.1590/S0103-20032009000100004

CAMPOS, A. L. S.; NAKAMURA, W. T. Rebalanceamento da Estrutura de Capital: Endividamento Setorial e Folga Financeira. Revista de Administração Contemporânea, v. 19, n. spe., p. 20-37, 2015. http://dx.doi.org/10.1590/1982-7849rac20151789

CAMPOS, A.; NAKAMURA, W. T. Folga Financeira Avaliada como Endividamento Relativo e Estrutura de Capital. Revista de Finanças Aplicadas, v. 1, n. 1, p. 1-19, 2013.

CASAS, R. La investigación Biotecnológica en México: Tendencias en el sector agroalimentario. Cuidad de México: Instituto de Investigaciones Sociales, Universidad Nacional Autónoma de México, 1993.

CORREA, C. A.; BASSO, L. F. C.; NAKAMURA, W. T. A Estrutura de Capital das Maiores Empresas Brasileiras: Análise Empírica das Teorias Pecking Order e Trade-Off, usando Panel Data. RAM, Revista de Administração Mackenzie, v. 14, n. 4, 2013.

COSTA, N.; CORREIA, T. A Estrutura de capital das empresas familiares Portuguesas à luz da teoria da agência. Revista dos Algarves, n. 16, p. 32-39, 2007.

DANIEL, F.; LOHRKE, F. T.; FORNACIARI, C. J.; TURNER, R. A. Slack resources and firm performance: a meta-analysis. Journal of Business Research, v. 57, n. 6, 2004. https://doi.org/10.1016/S0148-2963(02)00439-3

DENIS, D. J. Financial Flexibility and Corporate Liquidity. Journal of Corporate Finance, v. 17, n. 3, p. 667-674, 2011. https://doi.org/10.1016/j.jcorpfin.2011.03.006

DURAND, D. Cost of debt and equity funds for business: trends and problems of measurement. In Conference on research on business finance, NBER, 1952.

FIORENTINO, G.; BROSSI, L.; AMELONG, I.; CAMPANATTI, C.;. As oito grandes tendências de crescimento até 2020. Boston: Bain \& Company, Inc., 2012.

GARCIA, J. O. G. La actividad agrícola en México y el Mundo en el marco del sistema agroalimentario mundial: entre los agronegocios y el abasto de alimentos. INCEPTUM, v. 7, n. 13, p. 395-420, 2017.

GEORGE, G. Slack resources and the performance of privately held firms. Academy of Management Journal, v. 48, n. 4, p. 661-676, 2005. doi:10.5465/AMJ.2005.17843944

GRAHAM, J. R.; HARVEY, C. R. The theory and practice of corporate finance: Evidence from the field. Journal of Financial Economics, v. 60, n. 2, p. 187-243, 2001. https://doi.org/10.1016/S0304-405X(01)00044-7

HOFFMANN, P. S. Estructura de capital de las empresas que cotizan en la bolsa de valores chilena. Contaduría y Administración, n. 228, p. 41-66, 2009. 
KIM, H.; KIM, H.; LEE, P. M. Ownership structure and the relationship between financial slack and R\&D investments: Evidence from Korean firms. Organization Science, v. 19, n. 3, p. 404418, 2008. https://doi.org/10.1287/orsc. 1080.0360

MISHINA, Y.; POLLOCK, T. G.; PORAC, J. F. Are more resources always better for growth? Resource stickiness in market and product expansion. Strategic Management Journal, v. 25, n. 12, p. 1179-1197, 2004. doi:10.1002/smj.424

MODIGLIANI, F.; MILLER, M.H. Corporate income taxes and the cost of capital: correction. The American Economic Review, v. 70, n. 3, p. 433-443, 1963.

MODIGLIANI, F.; MILLER, M.H. The cost of capital, corporation finance and the theory of investment. The American Economic Review, v. 48, n. 3, p. 261-297, 1958.

MOUTON, M;, SMITH, N. Company Determinants of Capital Structure on the JSE Ltd and the Influence of the 2008 Financial Crisis. Journal of Economic and Financial Sciences, v. 9, n. 3, p. 789-806, 2016.

MYERS, S. C. The Capital Structure Puzzle. The Journal of Finance, v. 39, n. 3, 1984. doi:10.1111/j.1540-6261.1984.tb03646.x

MYERS, S.; MAJLUF, N. Corporate financing and investment decisions when firms have information that investors do not have. Journal of Financial Economics, v. 13, n. 2, p. 187 222, 1984. https://doi.org/10.1016/0304-405X(84)90023-0

NOHRIA, N.; GULATI, R. Is Slack Good or Bad for Innovation? Academy of Management Journal, v. 39, n. 5, p. 1245-1264, 1996. doi: 10.2307/256998

PEROBELLI, F. F. C.; FAMÁ, R. Fatores determinantes da estrutura de capital: aplicação a empresas de capital aberto no Brasil. Monografia. Universidade de São Paulo, Faculdade de Economia e Administração, São Paulo/SP, 2001.

PEROBELli, F. F. C.; FAMÁ, R. Fatores determinantes da estrutura de capital para empresas Latino-Americanas. Revista de Administração Contemporânea, Curitiba, v. 7, n. 1, p. 9-35, 2003. http://dx.doi.org/10.1590/S1415-65552003000100002

PROCHILE. Conhecendo o Chile através de seu setor agro e alimentos. Disponível em: $<$ http://www.prochile.gob.cl/int/brasil/wpcontent/blogs.dir/32/files_mf/1398260394Silvobaja. pdf>. Acesso em: 28 out. 2014.

RAJAN, R. G.; ZINGALES, L. What do we know about capital structure? Some evidence from international data. The Journal of Finance, v. 50, n. 5, p. 1421-1460, 1995.

RAO, J. O. Effect of Funding Sources on Financial Sustainability of Water Sector Institutions in Kenya. Master of Business Administration. University of Nairobi, Nairobi, 2013. 
SHARFMAN, M. P., WOLF, G., CHASE, R. B., TANSIK, D. A. Antecedents of organizational slack. Academy of Management Review, v. 13, n. 4, p. 601-614, 1988. doi: 10.5465/AMR.1988.4307484

SINGH, J. V. Performance, slack, and risk taking in organizational decision making. Academy of Management Journal, v. 29, n. 3, p. 562-585, 1986. doi: 10.2307/256224

SUNDER, S. L.; MYERS, S. C. Testing static tradeoff against pecking order models of capital structure. Journal of Financial Economics, v. 51, n. 2, p. 219-244, 1999. https://doi.org/10.1016/S0304-405X(98)00051-8

TITMAN, S.; WESSELS, R. The determinants of capital structure choice. The Journal of finance, v. 43, n. 1, p. 1-19, 1988. doi:10.1111/j.1540-6261.1988.tb02585.x

TRIPATHY, N.; ASIJA, A. The Impact of Financial Crisis on the Determinants of Capital Structure of Listed Firms in India. Journal of International Business and Economy, v. 18, n. 1, p. 101-121, 2017.

VANACKER, T.; COLLEWAERT, V.; ZAHRA, S. A. (2017). Slack resources, firm performance, and the institutional context: Evidence from privately held European firms. Strategic Management Journal, v. 38, n. 6, p. 1305-1326, 2017. doi:10.1002/smj.2583

ZAMBUTO, F.; LO NIGRO, G.; O'BRIEN, J. P. The Importance of Alliances in Firm Capital Structure Decisions: Evidence from Biotechnology Firms. Managerial and Decisions Economics, v. 38, n. 1, p. 2-18, 2017. doi: 10.1002/mde.2735

ZHONG, H. The Relationship between Slack Resources and Performance: an empirical study from China. International Journal of Modern Education and Computer Science (IJMECS), v. 3, n. 1, p. 1, 2011.

Uma versão prévia (preprint) deste artigo foi apresentado e publicado nos Anais do $6^{\circ}$ Congresso UFSC de Controladoria e Finanças 